\title{
ANALISIS USAHA INDUSTRI JENANG BERAS DI KABUPATEN PONOROGO
}

\author{
${ }^{1}$ Miftahul Dewi Afifah, ${ }^{2}$ Rahayu Relawati, ${ }^{3}$ Dyah Erni Widyastuti \\ ${ }^{1}$ Alumnus Prodi Agribisnis Fakultas Pertanian-Peternakan Universitas Muhammadiyah Malang \\ ${ }^{2,}{ }^{3}$ Staf Pengajar Prodi Agribisnis Fakultas Pertanian-Peternakan Universitas Muhammadiyah Malang \\ Email: rahayurelawati@umm.ac.id
}

\begin{abstract}
ABSTRAK
Salah satu olahan khas Kabupaten Ponorogo adalah Jenang Beras. Situasi pandemi Covid-19 menyebabkan ketidakpastian penjualan dan keuntungan usaha. Tujuan penelitian adalah 1) Menganalisis struktur biaya produksi usaha jenang beras di Kabupaten Ponorogo dan 2) Menganalisis keuntungan usaha jenang beras di Kabupaten Ponorogo. Metode penentuan lokasi dilakukan secara sengaja (purposive) di Kabupaten Ponorogo. Sampel dalam penelitian ini dilakukan secara purposive sampling atau dipilih secara sengaja yang telah memenuhi kriteria yakni memproduksi jenang beras, mempunyai tenaga kerja serta memiliki toko sendiri. Analisis yang digunakan dalam penelitian ini adalah analisis biaya, penerimaan dan keuntungan. Hasil penelitian ini adalah rata-rata biaya yang dikeluarkan oleh responden dalam satu bulan produksi yaitu Rp30.856.818,29 dan penerimaan rata-ratanya adalah sebesar Rp52.945.000,00, sedangkan keuntungan rata-rata yang diterima adalah sebesar Rp22.079.181,12 maka dapat disimpulkan usaha jenang beras ini menguntungkan bagi pengusaha.
\end{abstract}

Kata kunci : struktur biaya, keuntungan, jenang beras

\begin{abstract}
One of the typical preparations of the Ponorogo Regency is Rice Porridge. The Covid-19 pandemic situation has caused uncertainty in sales and business profits. The research objectives were 1) to analyze the production cost structure of the rice porridge business in Ponorogo Regency and 2) Analyze the profit of the rice porridge business in Ponorogo Regency. The method of determining the location was done purposively in Ponorogo Regency. The sample in this study was carried out by purposive sampling or was chosen deliberately who met the criteria, namely producing rice porridge, having a workforce, and having their shop. The analysis used in this research is the analysis of costs, revenues, and profit. The result of this research is that the average cost incurred by the respondents in one month of production is $\mathrm{Rp} 30.856 .818,29$ and the average income is $\mathrm{Rp52.945.000,00,} \mathrm{while} \mathrm{the} \mathrm{average} \mathrm{profit} \mathrm{received}$ is Rp22.079.181,18 it can be concluded that this rice porridge business is profitable for entrepreneurs.
\end{abstract}

Keywords: cost structure, profit, rice porridge 


\section{PENDAHULUAN}

Pembangunan di sektor industri merupakan salah satu prioritas utama dalam pembangunan ekonomi (Fathoni, Adi, \& Sutarto, 2016). Sektor industri memegang peranan yang penting bagi masyarakat di Indonesia termasuk masyarakat Kabupaten Ponorogo. Industri pengolahan adalah salah satu industri yang banyak diminati oleh masyarakat. Perusahaan industri pengolahan dibagi menjadi industri besar, industri sedang, industri kecil dan industri rumah tangga (BPS, 2020).

Industri rumah tangga yang berkembang saat ini salah satunya adalah Jenang, dikenal dengan nama Jenang Beras Khas Ponorogo. Usaha yang berbahan dasar tepung beras ini terbukti dapat memberikan pemasukan bagi pegiat industri dibidang olahan. Usaha ini memberikan peningkatan pendapatan untuk masyarakat. Masyarkat yang mengembangkan home industri ini terdapat dibeberapa daerah di Indonesia, salah satu pembuat jenang ini adalah di Ponorogo, tepatnya di Desa Josari Kecamatan Jetis Kabupaten Ponorogo. Nama produk jenang ini adalah Jenang Beras Mirah.

Penelitian mengenai analisis pendapatan maupun keuntungan sudah banyak digunakan oleh berbagai peneliti, antara lain (Fathoni et al., 2016) yang dilakukan di Kabupaten Sukoharjo pada usaha jenang krasikan; (Lukas, 2012) yang dilaksanakan di Kabupaten Kapuas tentang analisis biaya produksi dan pendapatan; dan (Mugiono \& Awani, 2014) tentang analisis pendapatan usaha gula merah di Kabupaten
Wonosobo. (Nurmahlina et al, 2020) memaparkan tentang analisis usaha dodol di Desa Telaga Bidadari. Penelitian lain juga dilakukan Ilahi (2020) yaitu analisis agroindustri dodol buah-buahn di Desa Buantan Besar. Penelitian mengenai jenang sudah banyak ditemukan, namun kebanyakan meneliti jenang ketan dan rasa buah-buahan.

Penelitian terkait jenang beras masih jarang ditemukan, sehingga perlu dilakukan untuk menganalisa biaya produksi dan keuntungan industri rumah tangga jenang besar ini. Berdasarkan latar belakang, tujuan penelitian ini adalah menganalisis struktur biaya produksi dan keuntungan usaha jenang beras di Kabupaten Ponorogo.

\section{METODE PENELITIAN}

Penelitian analisis biaya produksi dan pendapatan ini dilakukan di Kabupaten Ponorogo. Pemilihan daerah atau tempat penelitian dilakukan secara sengaja (purposive). Pemilihan tempat penetilian didasarkan atas pertimbangan bahwa Jenang Beras Mirah merupakan salah satu produsen jenang beras yang banyak dikenal oleh masyarakat wilayah Ponorogo.

Teknik pengambilan sampel dilakukan secara purposive sampling atau dipilih secara sengaja. Sampel yang dipilih adalah produsen jenang beras yang memenuhi kriteria: memproduksi jenang beras lebih dari 10 tahun dan toko.

Berdasarkan kriteria-kriteria ini, banyaknya responden atau produsen jenang beras yang memenuhi kriteria adalah sebanyak 3 home industri jenang beras. 
Jenis data yang digunakan adalah data primer dan diperkuat dengan data sekunder. Data primer merupakan data yang diperoleh secara langsung menggunakan kuesioner. Kuesioner disusun untuk menjawab beberapa pertanyaan yang dibutuhkan dalam proses pengumpulan data. Data yang dibutuhkan meliputi data biaya tetap, biaya variabel, penerimaan, dan keuntungan. Pengambilan data juga diambil melalui observasi secara langsung dan wawancara dengan pengolah jenang beras. Data sekunder merupakan data yang diperoleh dari penelitian terdahulu, studi literatur, dan sumber lain yang dibutuhkan dan terkait untuk mendukung data primer dalam proses analisis data.

Batasan istilah dan pengukuran variabel dalam penelitian ini digunakan untuk mengetahui ruang lingkup pembahasan, istilah-istilah tersebut yaitu :

Jenang beras merupakan jenis makanan yang diolah dari tepung beras, gula dan santan kelapa, jenang beras juga merupakan masakan khas Ponorogo. Biaya tetap adalah biaya yang pengeluarannya tidak dipengaruhi oleh besar kecilnya produksi yang dihasilkan, seperti mixer/pengaduk adonan, parutan kelapa, perasan kelapa, penggiling tepung, cetakan adonan, wajan besar dan ember, diukur dalam satuan $\mathrm{Rp}$ /proses produksi. Biaya variabel merupakan biaya yang pengeluarannya bisa berubah-ubah tergantung dari jumlah produk yang akan diproduksi seperti tepung beras, gula, santan kelapa, plastik, kertas minyak coklat dan kayu, diukur dalam satuan $\mathrm{Rp} / \mathrm{kg}$. Total biaya merupakan jumlah keseluruhan biaya yang dikeluarkan selama proses produksi, diukur dalam satuan $\mathrm{Rp} /$ proses produksi. Penerimaan merupakan nilai penjualan jenang yang dihasilkan, diukur dalam satuan Rp /proses produksi. Keuntungan merupakan selisih antara jumlah penerimaan atau hasil penjualan jenang dengan total biaya produksi yang telah dikeluarkan dalam satu kali proses produksi, diukur dalam satuan $\mathrm{Rp} /$ proses produksi.

Metode kuantitatatif untuk analisa data data primer yang diperoleh langsung dari pengamatanpengamatan di tiga industri jenang beras di Kabupaten Ponorogo. Data yang diperoleh dianalisis menggunakan analisis biaya dan keuntungan.

Analisis biaya dilakukan untuk mengetahui besarnya biaya yang dikeluarkan oleh pelaku usaha jenang beras dalam proses produksi. Secara matematis total biaya dapat dihitung menggunakan rumus :

$$
\mathrm{TC}=\mathrm{FC}+\mathrm{VC}
$$

Dimana;

$\mathrm{TC}=$ Total Cost, total biaya yang dikeluarkan selama satu kali produksi (Rupiah)

$\mathrm{FC}=$ Fixed Cost, biaya tetap yang dikeluarkan selama satu kali produksi (Rupiah)

$\mathrm{VC}=$ Variable Cost, biaya variabel yang dikeluarkan selama satu kali produksi (Rupiah)

Total biaya adalah jumlah biaya yag dikeluarkan oleh produsen dalam satu kali produksi, baik biaya tetap maupun biaya variabel. Biaya tetap meliputi penyusutan alat, dan sarana prasarana produksi seperti tungku, alat pengaduk, wajan besar, cetakan, mesin parutan kelapa, mesin penggiling dan lain-lain. Biaya variabel meliputi biaya bahan baku (tepung beras), biaya bahan penolong seperti gula dan santan kelapa, serta biaya pengemasan. 


\section{HASIL DAN PEMBAHASAN}

Biaya produksi serta biaya penerimaan dan keuntungan tentumemiliki perbedaan setiap kali proses produksi dan hari, baik masukan maupun pengeluaran setiap produsen. Begitu pula dengan produsen jenang beras yang diteliti. Perbedaan tersebut dipengaruhi oleh banyak sedikitnya produksi dan harga produk.

\section{Struktur Biaya Usaha Jenang Beras}

Biaya operasional adalah biaya yang berkaitan dengan modal kerja untuk kegiatan produksi (Sagay, Loho, $\&$ Tarore, 2019). Analisis biaya dapat diketahui melalui banyaknya biaya yang dikeluarkan selama proses produksi, meliputi biaya variabel dan tetap (Sultan, 2017). Biaya variabel merupakan biaya yang besar kecilnya berhubungan langsung dengan produksi sedangkan biaya tetap adalah semua jenis biaya yang tidak tergantung dengan besar kecilnya produksi. Jumlah biaya variabel sama dengan jumlah faktor produksi variabel dikalikan dengan biaya faktor produksi (Hanafie \& Rita, 2010). Biaya variabel mencakup bahan baku, bahan penunjang, kemasan dan lainlain sedangkan biaya tetap meliputi penyusutan alat.

a) Responden 1 (Bapak Handoko Mirah)

Biaya yang dikeluarkan responden 1 berupa biaya variabel dan tetap, dapat dijelaskan pada Tabel 1 .

Tabel 1. Biaya Variabel Responden 1

\begin{tabular}{clccrr}
\hline No. & Uraian & Satuan & Jumlah & Harga (Rp) & Total (Rp) \\
\hline 1 & Beras & $\mathrm{Kg}$ & 15 & 9.000 & 135.000 \\
2 & Gula & $\mathrm{Kg}$ & 15 & 12.000 & 180.000 \\
3 & Kelapa & $\mathrm{Biji}$ & 13 & 5.000 & 65.000 \\
4 & Bawang merah & $\mathrm{Kg}$ & 0,10 & 27.000 & 2.700 \\
5 & Plastik & Bungkus & 1 & 7.500 & 7.500 \\
6 & Kertas minyak & Rim & 1 & 40.000 & 40.000 \\
7 & Kayu & Anting & 30 & 5.000 & 150.000 \\
8 & Bensin & Liter & 5 & 9.200 & 46.000 \\
9 & Listrik & - & - & 2.000 & 2.000 \\
10 & Tenaga kerja & Orang & 5 & 70.000 & 350.000 \\
\hline & & Jumlah & & & $\mathbf{9 7 8 . 2 0 0}$ \\
\hline
\end{tabular}

Sumber : Data primer diolah, 2020

Tabel 1 menjelaskan bahwa biaya variabel dikeluarkan per satu kali produksi sebesar Rp978.200,00 dengan pengeluaran bahan baku berupa beras, gula, kelapa dan bawang merah. Bawang merah digunakan untuk bahan aroma dari jenang beras. 
Tabel 2. Biaya Tetap Responden 1

\begin{tabular}{clcrrr}
\hline No & Peralatan & Jumlah & Harga (Rp) & $\begin{array}{c}\text { Umur Ekonomis } \\
\text { (tahun) }\end{array}$ & Penyusutan Alat \\
\hline 1 & Mixer/pengaduk & 2 & 17.600 .000 & 20 & $4.821,92$ \\
2 & Parut kelapa & 1 & 275.000 & 6 & 125,57 \\
3 & Perasan kelapa & 1 & 12.000 .000 & 6 & 166,23 \\
4 & Penggiling & 1 & 8.550 .000 & 5 & $4.684,93$ \\
5 & Cetakan & 300 & 1.000 & 10 & 82,19 \\
6 & Wajan besar & 2 & 950.000 & 20 & 260,27 \\
7 & Ember/bak & 5 & 30.000 & 5 & 82,19 \\
\hline Jumlah & & & & $\mathbf{1 0 . 1 4 1 , 1 1}$ \\
\hline
\end{tabular}

Sumber : Data primer diolah, 2020

Tabel 2 menjelaskan bahwa penyusutan alat dari responden 1 sebesar Rp10.141,11 dan alat-alatnya berupa mixer/pengaduk jenang, parut kelapa, perasan kelapa, penggiling untuk tepung, cetakan jenang, wajan besar dan ember/bak. b) Responden 2 (Bapak Rudi Hartono)

Biaya yang dikeluarkan responden 2 berupa biaya variabel dan tetap, yang dapat dijelaskan pada tabel berikut.

Tabel 3. Biaya Variabel Responden 2

\begin{tabular}{cllrrr}
\hline No. & Uraian & Satuan & Jumlah & Harga (Rp) & \multicolumn{1}{c}{ Total (Rp) } \\
\hline 1 & Tepung beras & $\mathrm{Kg}$ & 15 & 12.000 & 180.000 \\
2 & Gula & $\mathrm{Kg}$ & 15 & 12.000 & 180.000 \\
3 & Kelapa & $\mathrm{Biji}$ & 13 & 5.000 & 65.000 \\
4 & Kertas minyak & Rim & 1 & 30.000 & 30.000 \\
5 & Kayu & Anting & 30 & 5.000 & 150.000 \\
6 & Bensin & Liter & 6 & 9.200 & 55.200 \\
7 & Listrik & - & - & 1.700 & 1.700 \\
8 & Tenaga kerja & Orang & 6 & 70.000 & 420.000 \\
\hline Jumlah & & & & $\mathbf{1 . 0 8 1 . 9 0 0}$ \\
\hline
\end{tabular}

Sumber : Data primer diolah, 2020

Tabel 3 memperlihatkan pengeluaran biaya variabel dari responden 2 , sebesar Rp1.081.900,00. Bahan yang digunakan adalah tepung beras, gula, dan kelapa kemudian bahan pengemasnya memakai kertas minyak coklat.

Tabel 4. Biaya Tetap Responden 2

\begin{tabular}{llcccr}
\hline No & Peralatan & $\begin{array}{c}\text { Jumlah } \\
\text { (Pcs) }\end{array}$ & Harga & $\begin{array}{c}\text { Umur Ekonomis } \\
\text { (tahun) }\end{array}$ & $\begin{array}{c}\text { Penyusutan } \\
\text { Alat }\end{array}$ \\
\hline 1 & Mixer/pengaduk & 1 & 16.650 .000 & 20 & 280,82 \\
2 & Parut kelapa & 1 & 265.000 & 15 & 48,40 \\
3 & Perasan kelapa & 1 & 15.000 .000 & 10 & 109,59 \\
4 & Cetakan & 300 & 1.500 & 10 & 123,29 \\
5 & Wajan besar & 1 & 865.000 & 20 & 118,49 \\
6 & Ember/bak & 4 & 25.000 & 3 & 91,32 \\
\hline Jumlah & & & & $\mathbf{6 . 7 7 1 , 9 2}$ \\
\hline
\end{tabular}

Sumber : Data primer diolah, 2020 
Tabel 4 menunujukkan biaya tetap yang dikeluarkan sebesar Rp6.771,92. Alatalat yang digunakan oleh produsen selama produksi adalah mixer/pengaduk jenang, parutan kelapa, perasan kelapa, cetakan jenang, wajan besar dan ember.

c) Responden 3 (Ibu Samikatun)

Biaya yang dikeluarkan responden 2 berupa biaya variabel dan biaya tetap, yang dapat dijelaskan pada tabel berikut.

Tabel 5. Biaya Variabel Responden 3

\begin{tabular}{clccrr}
\hline No. & \multicolumn{1}{c}{ Uraian } & Satuan & Jumlah & Harga (Rp) & \multicolumn{1}{c}{ Total (Rp) } \\
\hline 1 & Beras & Kg & 16 & 9.000 & 144.000 \\
2 & Gula & Kg & 16 & 12.000 & 192.000 \\
3 & Kelapa & Biji & 13 & 5.000 & 65.000 \\
4 & Plastik & Bungkus & 1 & 8.000 & 8.000 \\
5 & Kertas minyak & Rim & 1 & 30.000 & 30.000 \\
6 & Kayu & Anting & 30 & 5.000 & 150.000 \\
7 & Bensin & Liter & 5 & 9.200 & 46.000 \\
8 & Listrik & - & - & 2.200 & 2.200 \\
9 & Tenaga kerja & Orang & 6 & 60.000 & 360.000 \\
\hline Jumlah & & & & $\mathbf{9 9 7 . 2 0 0}$ \\
\hline
\end{tabular}

Sumber : Data primer diolah, 2020

Berdasarkan Tabel 5, biaya variabel yang dikeluarkan oleh produsen per satu kali produksi sebesar Rp997.200,00 dengan bahan baku yang relative sama dengan pada Tabel 6. Biaya Tetap Responden 3

\begin{tabular}{llcrrr}
\hline No & \multicolumn{1}{c}{ Peralatan } & $\begin{array}{c}\text { Jumlah } \\
\text { (Psc) }\end{array}$ & Harga (Rp) & $\begin{array}{c}\text { Umur Ekonomis } \\
\text { (tahun) }\end{array}$ & $\begin{array}{c}\text { Penyusutan } \\
\text { Alat }\end{array}$ \\
\hline 1 & Mixer/pengaduk & 1 & 17.750 .000 & 18 & $2.701,67$ \\
2 & Parut kelapa & 1 & 265.000 & 5 & 145,21 \\
3 & Perasan kelapa & 1 & 10.000 .000 & 5 & $5.479,45$ \\
4 & Penggiling & 1 & 6.755 .000 & 5 & $3.701,37$ \\
5 & Cetakan & 350 & 1.000 & 20 & 47,95 \\
6 & Wajan besar & 1 & 990.000 & 18 & 150,68 \\
7 & Ember/bak & 5 & 30.000 & 3 & 136,99 \\
8 & Cukil kelapa & 5 & 2.000 & 5 & 5,48 \\
\hline Jumlah & & & & & $\mathbf{1 2 . 3 6 8 , 8 0}$ \\
\hline
\end{tabular}

Sumber : Data primer diolah, 2020

Tabel 6 menyajikan besarnya pengeluaran untuk biaya tetap dari usaha jenang beras responden 3 adalah Rp12.368,80. Alat-alat seperti mixer/pengaduk jenang, parutan kelapa, perasan kelapa, penggiling, wajan, cetakan dan cukil kelapa.

\section{Keuntungan Usaha Jenang Beras}

Perbedaan rincian besarnya biaya yang dikeluarkan serta penerimaan dan keuntungan setiap satu kali proses produksi responden lainnya, seperti beras, gula dan kelapa, kemudian bahan pengemasnya adalah plastik dan kertas minyak coklat. 
Tabel 7. Biaya, Penerimaan dan Keuntungan Setiap Satu Kali Proses Produksi

\begin{tabular}{|c|c|c|c|c|}
\hline \multirow[t]{2}{*}{ Uraian } & \multicolumn{2}{|r|}{ Responden } & \multirow[t]{2}{*}{ Responden } & Responden \\
\hline & $\mathbf{1}$ & & & 3 \\
\hline Biaya variabel & & $978.200,00$ & $1.081 .900,00$ & $997.200,00$ \\
\hline Biaya tetap & & $10.141,11$ & $6.771,92$ & $12.368,80$ \\
\hline Biaya total & & $988.341,11$ & $1.088 .671,92$ & $1.009 .568,80$ \\
\hline Penerimaan & & $1.500 .000,00$ & $2.222 .500,00$ & $1.572 .000,00$ \\
\hline Keuntungan & & $511.658,89$ & $1.133 .828,08$ & $562.431,20$ \\
\hline
\end{tabular}

Sumber: Data primer diolah, 2020

Tabel 7 menunjukkan bahwa biaya produksi dan penerimaan tertinggi adalah usaha milik responden kedua yaitu Bapak Rudi Hartono dengan penerimaan rata-rata sebesar Rp2.222.500,00; selanjutnya rata-rata penerimaan sebesar Rp1.572.000,00 pada usaha jenang beras milik Ibu Samikatun dan yang terakhir adalah usaha milik Bapak Handoko Mirah dengan jumlah ratarata penerimaan sebesar Rp1.500.000,00. Perbedaan perolehan penerimaan tersebut disebabkan oleh banyak sedikitnya produksi dan juga perbedaan dari harga masing-masing produk tersebut. Keuntungan responden pertama adalah sebesar Rp511.658,89, responden kedua sebesar Rp1.133.828,08 dan responden yang ketiga adalah sebesar Rp562.431,20 setiap satu kali proses produksi.

Rata-rata keuntungan suatu usaha berbeda dan perbedaan ini dipengaruhi oleh jumlah produk yang dijual, harga jual, dan biaya yang dikeluarkan. Hal ini sesuai dengan pendapat (Fathoni et al., 2016), bahwa semakin banyak produk yang diproduksi dengan biaya rendah dan semakin tinggi harga produk maka keuntungan yang diperoleh semakin besar.

\section{SIMPULAN DAN SARAN \\ Kesimpulan \\ Berdasarkan hasil dari penelitian dan analisis yang dilakukan, maka dapat diperoleh kesimpulan sebagai berikut; \\ 1. Struktur biaya meliputi biaya variabel dan biaya tetap. Biaya variabel rata-rata yang dikeluarkan oleh ketiga responden adalah sebesar Rp1.019.100,00 dan rata- rata biaya tetap adalah sebesar Rp9.760,61.}

2. Rata-rata keuntungan yang diperoleh ketiga responden adalah sebesar Rp735.972,72 per satu kali produksi dan sebesar Rp22.079.181,71 selama satu bulan produksi.

\section{Saran}

1. Bagi pengembang usaha industri jenang beras di Kabupaten Ponorogo agar lebih giat lagi dalam meningkatkan nilai produksi, dengan menambah kreatifitas kemasan produk dan cita rasa sehingga mampu menciptakan perkembanga usaha yang lebih efisien.

2. Hasil dari penelitian ini dapat dijadikan acuan bagi peneliti selanjutnya, sehingga dapat memaksimalkan dan mengembangkan lebih dalam dari penelitian ini. 
Miftahul Dewi Afifah, Rahayu Relawati, Dyah Erni Widyastuti

\section{DAFTAR PUSTAKA}

BPS. Badan Pusat Statistika (2020). Tersedia pada: https://www.bps.go.id/subject/9/ industri-besar-dan-sedang.html.

Fathoni, M. I., Adi, K., \& Sutarto. (2016). Analisis Usaha Industri Jenang Krasikan Di Kabupaten Sukoharjo. AGRISTA, 4(3), 392404.

Hanafie, \& Rita. (2010). Pengantar Ekonomi Pertanian. Yogyakarta.

Ilahi, R. dan D. (2020). Analisis Agroindustri Dodol BuahBuahan di Desa Buantan Besar Kecamatan Siak Kabupaten Siak (Studi Kasus UD. Putra Mandiri). Jurnal Agribisnis, 22(2).

Lukas. (2012). Analisis Biaya Produksi dan Pendapatan Budidaya Ikan Patin (Pangasius pangasius) di Kabupaten Kapuas. Jurnal Ilmu Hewani Tropika, 1(1), 36-39.
Analisis Usaha Industri Jenang Beras di Kabupaten Ponorogo

Mugiono, S. M., \& Awani, S. N. (2014). Analisis Pendapatan Usahagula Merah Kelapa (Studi Kasus Di Desa Medono Kecamatan Kaliwiro Kabupaten Wonosobo). Jurnal Ilmu Pertanian, 10(2), 22-31.

Nurmahlina et al. (2020). Analisis Usaha Dodol Kandangan Di Desa Telaga Bidadari, Kecamatan Sungai Raya, Kabupaten Hulu Sungai Selatan (Studi Kasus: Dodol, Mama Alfi). Frontier Agribisnis, 1(4), 83-84.

Sagay, K. I. G., Loho, A. E., \& Tarore, M. L. G. (2019). Analisis Finansial Usaha Dodol Salak (Studi Kasus: UD Mandiri Di Desa Pangu Satu Kecamatan Ratahan Timur Kabupaten Minahasa Tenggara). AgriSosioekonomi, 15(1), 169-178. https://doi.org/10.35791/agrsose k.15.1.2019.23593

Sultan. (2017). Analisis Kelayakan Usaha Baje Dodol KUB IK Cipta Usaha Kelurahan Anreapi Kecamatan Anreapi Kabupaten Polewali Mandar. Jurnal Imu Pertanian, 2(2), 24-29. 